\title{
Effects of Polychlorinated Biphenyls on Lignin Biosynthesis in Arabidopsis thaliana
}

Fanella Zamcho ${ }^{\mathrm{a}}$, Aaron Newborn ${ }^{\mathrm{a}}$, Ayesha Karamat ${ }^{\mathrm{a}}$, Rouzbeh Tehrani ${ }^{\mathrm{b}}$, Nancy Pleshko ${ }^{\mathrm{c}}$, Benoit Van Akena,*

${ }^{a}$ Department of Chemistry \& Biochemistry, George Mason University, Fairfax, Virginia, United States

${ }^{b}$ Department of Civil \& Environmental Engineering, Temple University, Philadelphia, Pennsylvania, United States

${ }^{c}$ Department of Bioengineering, Temple University, Philadelphia, Pennsylvania, United States

* Corresponding author:

Department of Chemistry \& Biochemistry

George Mason University, Fairfax, Virginia, USA

Phone: 703-993-1091

Email: bvanaken@gmu.edu 


\section{Supporting Information}

Table S1. List of primers used for the quantitative reverse-transcription PCR (qRT-PCR) of selected genes

\begin{tabular}{|c|c|c|c|}
\hline TAIR ID & Gene Description & & Primer Sequences $\left(5^{\prime} \rightarrow 3^{\prime}\right)$ \\
\hline \multirow[t]{2}{*}{ AT4G08770 } & \multirow[t]{2}{*}{ Apoplastic peroxidase Prx37 } & Forward & TCGTTGCTCTTTCTGGTGGTC \\
\hline & & Reverse & AGTGTTACTGAAGTTATAAAGCCGA \\
\hline \multirow[t]{2}{*}{ AT5G05340 } & \multirow{2}{*}{$\begin{array}{l}\text { Peroxidases involved in lignin } \\
\text { biosynthesis }\end{array}$} & Forward & AGACTCCGTCGTAGCCCTTG \\
\hline & & Reverse & TGTTACTATTCGCTGCCGCT \\
\hline \multirow{2}{*}{ AT1G67980 } & \multirow{2}{*}{$\begin{array}{l}\text { S-adenosyl-L-methionine: } \\
\text { transcaffeoyl Coenzyme A 3-O- } \\
\text { methyltransferase }\end{array}$} & Forward & ACCTGAAGATGGCCGTATTACC \\
\hline & & Reverse & TCTTGTGATCAACACCAGCCT \\
\hline \multirow[t]{2}{*}{ AT3G49120 } & \multirow[t]{2}{*}{ Class III peroxidase Perx34 } & Forward & TCACTAACATCGTACGAGAAACCA \\
\hline & & Reverse & TGGATGCGTCACAACCATTA \\
\hline \multirow[t]{2}{*}{ AT2G44480 } & \multirow[t]{2}{*}{ Beta glucosidase 17} & Forward & CGTCTTTCGACCTCTCTCCA \\
\hline & & Reverse & GGCTGCTCCTTCACTCTGAT \\
\hline \multirow[t]{2}{*}{ AT5G66390 } & \multirow{2}{*}{$\begin{array}{l}\text { Peroxidases involved in lignin } \\
\text { biosynthesis }\end{array}$} & Forward & GTCTCCCTCTCAGGAAGTCAC \\
\hline & & Reverse & GCTTTCCGTTGCCGGATTG \\
\hline \multirow[t]{2}{*}{ AT1G05260 } & \multirow{2}{*}{$\begin{array}{l}\text { Cationic peroxidase involved in the } \\
\text { stress responses }\end{array}$} & Forward & TGTCGTTTTCACCGGAGGAC \\
\hline & & Reverse & TCCGCTGCGTTTGATATCCT \\
\hline \multirow[t]{2}{*}{ AT5G66690 } & \multirow{2}{*}{$\begin{array}{l}\text { UDPG:coniferyl alcohol } \\
\text { glucosyltransferase }\end{array}$} & Forward & ACACATCATTAACAAAACAAAGCCT \\
\hline & & Reverse & TCCGGGACTGGAAAACATGG \\
\hline \multirow[t]{2}{*}{ AT2G27550 } & \multirow[t]{2}{*}{ Protein similar to TFL1 } & Forward & AGAGAGCACTTGCACTGGATT \\
\hline & & Reverse & ATCCCTATGTTTGGCCGAGG \\
\hline \multirow[t]{2}{*}{ AT1G69880 } & \multirow[t]{2}{*}{ Thioredoxin H-type 8} & Forward & CCAAAGCTCGAAGAGTTGGC \\
\hline & & Reverse & AACTCCATCCACACGCTCATT \\
\hline \multirow[t]{2}{*}{ AT3G44350 } & \multirow[t]{2}{*}{ NAC domain containing protein 61} & Forward & CGGAAAAGCACCTACTGGGA \\
\hline & & Reverse & GAATTCGGGCCTCAACTTTGG \\
\hline \multirow[t]{2}{*}{ AT1G19250 } & \multirow{2}{*}{$\begin{array}{l}\text { Flavin-dependent monooxygenase } \\
\text { FMO1 }\end{array}$} & Forward & GTAGCCGTCATCGGCTTCAA \\
\hline & & Reverse & AGCTTTTCCTCCTTCCCCTTG \\
\hline \multirow[t]{2}{*}{ AT5G18010 } & \multirow[t]{2}{*}{ Small auxin up RNA 19} & Forward & TGCGGTGTACGTAGGAGAGA \\
\hline & & Reverse & TGACGGTTGGCTCAAGTATGA \\
\hline \multirow[t]{2}{*}{ AT5G57640 } & \multirow[t]{2}{*}{ GCK domain-containing protein } & Forward & CTGGTGAGGCTAGAGCGATG \\
\hline & & Reverse & TAAACGCCCTCGCAATGACT \\
\hline \multirow[t]{2}{*}{ AT4G25580 } & CAP160 protein & Forward & GATCCCACCGGTAAAGGAGC \\
\hline & & Reverse & CTCCCGGAGATCTCTTCCCA \\
\hline AT5G18020 & SAUR-like auxin-responsive protein & Forward & CTCCACCACAGCAGCCTC \\
\hline & family & Reverse & ТСТCTTCTTTTGGCTCTCACCT \\
\hline AT3G41768 & 18S Ribosomal DNA (rDNA) & Forward & CTCCACCACAGCAGCCTC \\
\hline & & Reverse & ТСТCTTCTTTTGGCTCTCACCT \\
\hline AT1G13320 & Ser/Thr protein phosphatase $2 \mathrm{~A}$ & Forward & TAACGTGGCCAAAATGATGC \\
\hline & & Reverse & GTTCTCCACAACCGCTTGGT \\
\hline
\end{tabular}


Table S2. Comparison of fold change of selected Arabidopsis genes exposed to 2,5-DCB as measured by RNA sequencing and qRTPCR. The Pearson's correlation coefficients $(r)$ show the association between the fold changes measured with the two methods. The statistical significance of the RNA sequencing fold changes is given by the false discovery rate (FRD)-adjusted $p$-value (Bonferroni) returned by the DESeq2 software. The statistical significance of the qRT-PCR fold changes is given by the $t$-test $p$-value comparing the delta $\mathrm{C}_{\mathrm{T}}$ values of the exposed samples with the controls

\begin{tabular}{|c|c|c|c|c|c|c|}
\hline \multirow[t]{2}{*}{ TAIR ID } & \multirow[t]{2}{*}{ Description } & \multicolumn{2}{|c|}{ RNA Seq } & \multicolumn{2}{|c|}{ qRT-PCR } & \multirow[t]{2}{*}{ Pearson $r$} \\
\hline & & Fold change & Adj. $p$-value & Fold change & $p$-value & \\
\hline \multicolumn{7}{|c|}{ Downregulated Genes } \\
\hline AT4G08770 & Apoplastic peroxidase $\operatorname{Prx} 37$ & 13.26 & 0.00 & 15.01 & 0.002 & 0.964 \\
\hline AT5G05340 & Peroxidases involved in lignin biosynthesis & 10.81 & 0.00 & 13.46 & 0.010 & 0.932 \\
\hline AT1G67980 & $\begin{array}{l}\text { S-adenosyl-L-methionine: transcaffeoyl Coenzyme } \\
\text { A 3-O-methyltransferase }\end{array}$ & 7.32 & 0.00 & 10.19 & 0.004 & 0.974 \\
\hline AT3G49120 & Class III peroxidase Perx34 & 3.64 & 0.00 & 3.65 & 0.027 & 0.644 \\
\hline AT2G44480 & Beta glucosidase 17 & 2.87 & 0.00 & 2.38 & 0.016 & 0.817 \\
\hline AT5G66390 & Peroxidase involved in lignin biosynthesis. & 2.71 & 0.00 & 2.46 & 0.062 & 0.985 \\
\hline AT1G05260 & Cationic peroxidase involved in the stress responses & 2.19 & 0.01 & 1.80 & 0.169 & 0.925 \\
\hline AT5G66690 & UDPG:coniferyl alcohol glucosyltransferase & 2.02 & 0.04 & 2.33 & 0.034 & 0.980 \\
\hline \multicolumn{7}{|c|}{ Downregulated Genes } \\
\hline AT2G27550 & Protein similar to TFL1 & 68.01 & 0.00 & 68.80 & 0.001 & 0.854 \\
\hline AT1G69880 & Thioredoxin H-type 8 & 45.69 & 0.00 & 61.56 & 0.001 & 0.975 \\
\hline AT3G44350 & NAC domain containing protein 61 & 35.27 & 0.00 & 13.29 & 0.000 & 0.981 \\
\hline AT1G19250 & Flavin-dependent monooxygenase FMO1 & 30.82 & 0.00 & 3.81 & 0.234 & -0.002 \\
\hline \multicolumn{7}{|c|}{ Downregulated Genes } \\
\hline AT5G18010 & Small auxin up RNA 19 & 0.23 & 0.00 & 0.76 & 0.000 & 0.927 \\
\hline AT5G57640 & GCK domain-containing protein & 0.23 & 0.00 & 0.16 & 0.004 & 0.097 \\
\hline AT4G25580 & CAP160 protein & 0.23 & 0.00 & 0.25 & 0.001 & 0.950 \\
\hline AT5G18020 & SAUR-like auxin-responsive protein family & 0.20 & 0.00 & 0.22 & 0.000 & 0.994 \\
\hline
\end{tabular}


Table S3. Comparison of fold change of selected Arabidopsis genes exposed to 4'-OH-2,5-DCB as measured by RNA sequencing and qRT-PCR. The statistical significance of the fold changes obtained from RNA sequencing is represented by adjusted $p$-value (Bonferroni). The statistical significance of the fold changes obtained from qRT-PCR is represented by the $t$-test $p$-value comparing the delta $C_{T}$ values. The Pearson's correlation coefficients $(r)$ show the association between the fold changes measured with the two methods.

\begin{tabular}{|c|c|c|c|c|c|c|}
\hline \multirow[t]{2}{*}{ TAIR ID } & \multirow[t]{2}{*}{ Description } & \multicolumn{2}{|c|}{ RNA Seq } & \multicolumn{2}{|c|}{ qRT-PCR } & \multirow[t]{2}{*}{ Pearson $r$} \\
\hline & & Fold change & Adj. $p$-value & Fold change & $p$-value & \\
\hline \multicolumn{7}{|c|}{ Downregulated Genes } \\
\hline AT4G08770 & Apoplastic peroxidase Prx37 & 6.43 & 0.00 & 6.48 & 0.002 & 1.000 \\
\hline AT5G05340 & Peroxidases involved in lignin biosynthesis & 3.07 & 0.02 & 4.08 & 0.017 & 0.998 \\
\hline AT1G67980 & $\begin{array}{l}\text { S-adenosyl-L-methionine: transcaffeoyl Coenzyme } \\
\text { A 3-O-methyltransferase }\end{array}$ & 2.30 & 0.03 & 2.79 & 0.015 & 0.997 \\
\hline AT3G49120 & Class III peroxidase Perx34 & 2.73 & 0.00 & 2.70 & 0.010 & 0.968 \\
\hline AT2G44480 & Beta glucosidase 17 & 2.71 & 0.00 & 2.53 & 0.039 & 0.725 \\
\hline AT5G66390 & Peroxidase involved in lignin biosynthesis. & 9.21 & 0.00 & 9.57 & 0.000 & 0.995 \\
\hline AT1G05260 & Cationic peroxidase involved in the stress responses & 6.62 & 0.00 & 6.88 & 0.001 & 0.926 \\
\hline AT5G66690 & UDPG:coniferyl alcohol glucosyltransferase & 4.88 & 0.00 & 6.04 & 0.002 & 0.988 \\
\hline \multicolumn{7}{|c|}{ Downregulated Genes } \\
\hline AT2G27550 & Protein similar to TFL1 & 106.84 & 0.00 & 108.11 & 0.000 & 0.947 \\
\hline AT1G69880 & Thioredoxin H-type 8 & 26.00 & 0.00 & 17.33 & 0.001 & 0.810 \\
\hline AT3G44350 & NAC domain containing protein 61 & 51.85 & 0.00 & 20.93 & 0.000 & 0.991 \\
\hline AT1G19250 & Flavin-dependent monooxygenase FMO1 & 14.29 & 0.00 & 1.66 & 0.312 & 0.999 \\
\hline \multicolumn{7}{|c|}{ Downregulated Genes } \\
\hline AT5G18010 & Small auxin up RNA 19 & 0.23 & 0.00 & 1.58 & 0.001 & 0.961 \\
\hline AT5G57640 & GCK domain-containing protein & 0.11 & 0.00 & 0.07 & 0.001 & 0.792 \\
\hline AT4G25580 & CAP160 protein & 0.09 & 0.00 & 0.13 & 0.001 & 0.926 \\
\hline AT5G18020 & SAUR-like auxin-responsive protein family & 0.23 & 0.00 & 0.19 & 0.000 & 0.811 \\
\hline
\end{tabular}


Table S4. Enrichment of different gene categories as obtained with DAVID. Fold-enrichment values are given together with the Bonferroni-adjusted $p$-value. Only terms with enrichment values $>1.5$ and Bonferroni-adjusted $p$-value $<0.05$ are shown

\begin{tabular}{|c|c|c|c|c|c|}
\hline & & PCB & & ОН-РCB & \\
\hline Category & Term & $\begin{array}{c}\text { Fold } \\
\text { Enrichment }\end{array}$ & $\begin{array}{l}\text { Adjusted } \\
p \text {-value }\end{array}$ & $\begin{array}{c}\text { Fold } \\
\text { Enrichment }\end{array}$ & $\begin{array}{c}\text { Adjusted } \\
p \text {-value }\end{array}$ \\
\hline \multirow{5}{*}{$\begin{array}{l}\text { Metabolic } \\
\text { Pathways } \\
\text { (KEGG) }\end{array}$} & Phenylpropanoid biosynthesis & 5.10 & 0.00 & 4.87 & 0.00 \\
\hline & Plant-pathogen interaction & 4.27 & 0.00 & 4.34 & 0.00 \\
\hline & Glutathione metabolism & 3.91 & 0.00 & 3.39 & 0.00 \\
\hline & Biosynthesis of secondary metabolites & 1.55 & 0.01 & 1.59 & 0.00 \\
\hline & Alpha-linolenic acid metabolism & - & - & 4.17 & 0.01 \\
\hline \multirow{16}{*}{$\begin{array}{l}\text { Biological } \\
\text { Processes } \\
\text { (GOTERM) }\end{array}$} & Amino sugar metabolic process & 13.33 & 0.00 & 8.38 & 0.00 \\
\hline & Chitin catabolic process & 7.20 & 0.01 & 5.48 & 0.00 \\
\hline & Toxin catabolic process & 6.09 & 0.00 & 4.47 & 0.00 \\
\hline & Hydrogen peroxide catabolic process & 5.62 & 0.00 & 5.01 & 0.00 \\
\hline & Response to toxic substance & 5.57 & 0.00 & 3.93 & 0.00 \\
\hline & Glutathione metabolic process & 4.84 & 0.00 & 3.87 & 0.00 \\
\hline & Response to oxidative stress & 3.37 & 0.00 & 2.91 & 0.00 \\
\hline & Protein phosphorylation & 2.02 & 0.00 & 2.06 & 0.00 \\
\hline & Oxidation-reduction process & 1.55 & 0.01 & 1.57 & 0.00 \\
\hline & Cellular response to iron ion starvation & - & - & 10.00 & 0.01 \\
\hline & $\begin{array}{l}\text { Cell wall macromolecule catabolic } \\
\text { process }\end{array}$ & - & - & 5.27 & 0.00 \\
\hline & $\begin{array}{l}\text { Cell surface receptor signaling } \\
\text { pathway }\end{array}$ & - & - & 3.96 & 0.00 \\
\hline & Plant-type cell wall organization & - & - & 3.77 & 0.00 \\
\hline & Flavonoid glucuronidation & - & - & 2.75 & 0.00 \\
\hline & Ethylene-activated signaling pathway & - & - & 2.55 & 0.00 \\
\hline & Flavonoid biosynthetic process & - & - & 2.44 & 0.01 \\
\hline \multirow{8}{*}{$\begin{array}{l}\text { Metabolic } \\
\text { Functions } \\
\text { (GOTERM) }\end{array}$} & Chitinase activity & 9.06 & 0.00 & 5.55 & 0.00 \\
\hline & Chitin binding & 6.87 & 0.05 & - & - \\
\hline & Oxalate decarboxylase activity & 6.18 & 0.03 & - & - \\
\hline & Peroxidase activity & 5.28 & 0.00 & 4.84 & 0.00 \\
\hline & Glutathione transferase activity & 4.98 & 0.00 & 3.73 & 0.00 \\
\hline & UDP-glycosyltransferase activity & 3.47 & 0.01 & 2.86 & 0.00 \\
\hline & ADP binding & 2.91 & 0.00 & 2.79 & 0.00 \\
\hline & $\begin{array}{l}\text { Transferase activity, transferring } \\
\text { hexosyl groups }\end{array}$ & 2.89 & 0.01 & 2.47 & 0.00 \\
\hline
\end{tabular}




\begin{tabular}{|c|c|c|c|c|}
\hline Heme binding & 2.67 & 0.00 & 2.61 & 0.00 \\
\hline Carbohydrate binding & 2.63 & 0.00 & - & - \\
\hline $\begin{array}{l}\text { Transcription regulatory region DNA } \\
\text { binding }\end{array}$ & 2.20 & 0.02 & 2.36 & 0.00 \\
\hline Kinase activity & 1.98 & 0.00 & 1.91 & 0.00 \\
\hline Protein serine/threonine kinase activity & 1.90 & 0.00 & 2.04 & 0.00 \\
\hline AT DNA binding & - & - & 7.23 & 0.00 \\
\hline Structural constituent of cell wall & - & - & 5.44 & 0.00 \\
\hline Polysaccharide binding & - & - & 3.00 & 0.00 \\
\hline $\begin{array}{l}\text { Quercetin 7-O-glucosyltransferase } \\
\text { activity }\end{array}$ & - & - & 2.75 & 0.01 \\
\hline $\begin{array}{l}\text { Quercetin 3-O-glucosyltransferase } \\
\text { activity }\end{array}$ & - & - & 2.70 & 0.01 \\
\hline Calcium ion binding & - & - & 2.34 & 0.00 \\
\hline $\begin{array}{l}\text { Transcription factor activity, RNA } \\
\text { polymerase II transcription factor } \\
\text { recruiting }\end{array}$ & - & - & 2.30 & 0.04 \\
\hline Oxygen binding & - & - & 2.13 & 0.00 \\
\hline Sequence-specific DNA binding & - & - & 1.97 & 0.00 \\
\hline $\begin{array}{l}\text { Transcription factor activity, sequence- } \\
\text { specific DNA binding }\end{array}$ & - & - & 1.43 & 0.00 \\
\hline $\begin{array}{l}\text { Concanavalin A-like lectin/glucanase, } \\
\text { subgroup }\end{array}$ & 3.19 & 0.00 & 3.20 & 0.00 \\
\hline Plant peroxidase & 7.27 & 0.00 & 6.29 & 0.00 \\
\hline $\begin{array}{l}\text { Haem peroxidase, } \\
\text { plant/fungal/bacterial }\end{array}$ & 6.56 & 0.00 & 5.68 & 0.00 \\
\hline Haem peroxidase & 6.41 & 0.00 & 5.68 & 0.00 \\
\hline Peroxidases heam-ligand binding site & 6.97 & 0.00 & 6.22 & 0.00 \\
\hline Peroxidase, active site & 7.53 & 0.00 & 6.96 & 0.00 \\
\hline $\begin{array}{l}\text { Serine-threonine/tyrosine-protein } \\
\text { kinase catalytic domain }\end{array}$ & 2.73 & 0.00 & 2.55 & 0.00 \\
\hline Leucine-rich repeat, typical subtype & 3.80 & 0.00 & 2.60 & 0.00 \\
\hline Leucine-rich repeat & 2.77 & 0.00 & 2.23 & 0.00 \\
\hline Protein kinase, catalytic domain & 1.89 & 0.00 & 1.95 & 0.00 \\
\hline $\begin{array}{l}\text { Toll/interleukin-1 receptor homology } \\
\text { (TIR) domain }\end{array}$ & 4.02 & 0.00 & 4.28 & 0.00 \\
\hline $\begin{array}{l}\text { AAA-type ATPase, N-terminal } \\
\text { domain }\end{array}$ & 10.29 & 0.00 & 5.71 & 0.00 \\
\hline $\begin{array}{l}\text { Serine/threonine-protein kinase, active } \\
\text { site }\end{array}$ & 1.97 & 0.00 & 2.09 & 0.00 \\
\hline Protein kinase-like domain & 1.82 & 0.00 & 1.91 & 0.00 \\
\hline Protein kinase, ATP binding site & 2.05 & 0.00 & 2.15 & 0.00 \\
\hline Glutathione S-transferase, $\mathrm{N}$-terminal & 5.47 & 0.00 & 3.98 & 0.00 \\
\hline
\end{tabular}




\begin{tabular}{|c|c|c|c|c|}
\hline RmlC-like jelly roll fold & 4.22 & 0.00 & - & - \\
\hline $\begin{array}{l}\text { Glutathione S-transferase, C-terminal- } \\
\text { like }\end{array}$ & 5.06 & 0.00 & 3.69 & 0.00 \\
\hline $\begin{array}{l}\text { Glycoside hydrolase, family } 19, \\
\text { catalytic }\end{array}$ & 12.30 & 0.00 & 8.53 & 0.00 \\
\hline Germin, manganese binding site & 8.28 & 0.00 & - & - \\
\hline Lysozyme-like domain & 11.48 & 0.00 & 7.96 & 0.00 \\
\hline $\begin{array}{l}\text { Leucine-rich repeat-containing N- } \\
\text { terminal, type } 2\end{array}$ & 2.78 & 0.00 & 2.34 & 0.00 \\
\hline Extensin repeat & 10.13 & 0.00 & 9.13 & 0.00 \\
\hline $\begin{array}{l}\text { UDP-glucuronosyl/UDP- } \\
\text { glucosyltransferase }\end{array}$ & 3.53 & 0.01 & 2.98 & 0.00 \\
\hline Germin & 6.73 & 0.01 & - & - \\
\hline NB-ARC & 2.91 & 0.02 & 2.93 & 0.00 \\
\hline Chitin-binding, type 1 , conserved site & 14.35 & 0.02 & - & - \\
\hline RmlC-like cupin domain & 4.07 & 0.02 & - & - \\
\hline Chitin-binding, type 1 & 12.91 & 0.03 & - & - \\
\hline $\begin{array}{l}\text { Wall-associated receptor kinase } \\
\text { galacturonan-binding domain }\end{array}$ & - & - & 6.51 & 0.00 \\
\hline AP2/ERF domain & - & - & 3.19 & 0.00 \\
\hline EF-Hand 1, calcium-binding site & - & - & 3.06 & 0.00 \\
\hline DNA-binding, integrase-type & - & - & 2.95 & 0.00 \\
\hline EF-hand domain & - & - & 2.89 & 0.00 \\
\hline Leucine-rich repeat 3 & - & - & 3.73 & 0.00 \\
\hline EF-hand-like domain & - & - & 2.58 & 0.00 \\
\hline Wall-associated kinase & - & - & 7.96 & 0.00 \\
\hline NADPH oxidase Respiratory burst & - & - & 9.55 & 0.00 \\
\hline Cytochrome P450 & - & - & 2.11 & 0.00 \\
\hline $\begin{array}{l}\text { EGF-like calcium-binding, conserved } \\
\text { site }\end{array}$ & - & - & 5.71 & 0.00 \\
\hline Predicted AT-hook DNA-binding & - & - & 7.35 & 0.00 \\
\hline Cytochrome P450, E-class, group I & - & - & 2.02 & 0.00 \\
\hline
\end{tabular}



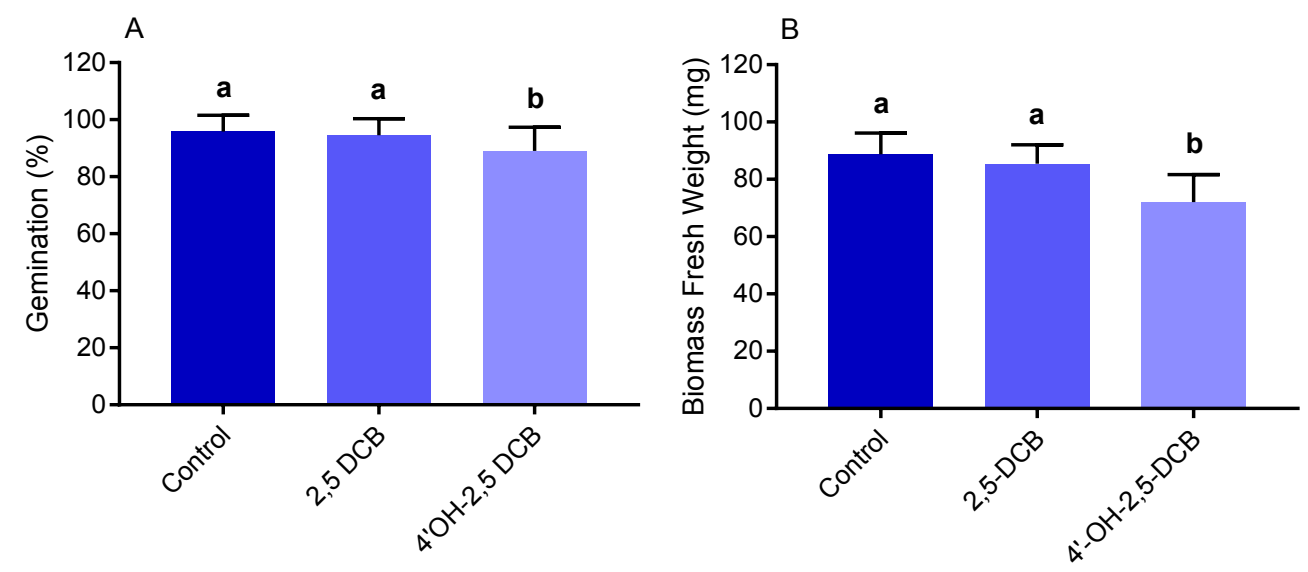

Figure S1. Toxicity of 2,5-DCB and 4'-OH-2,5-DCB toward Arabidopsis plantlets as determined through 7-day germination tests (panel A) and 5-week growth tests (panel B). 2,5-DCB and 4'$\mathrm{OH}-2,5-\mathrm{DCB}$ were applied at a concentration 25 and $5 \mathrm{mg} \mathrm{L}^{-1}$, respectively. The error bars represent the standard deviations between biological replicates $(\mathrm{n}=18)$. Different letters indicate statistically significant differences between treatments ( $t$-test, 95\% confidence).

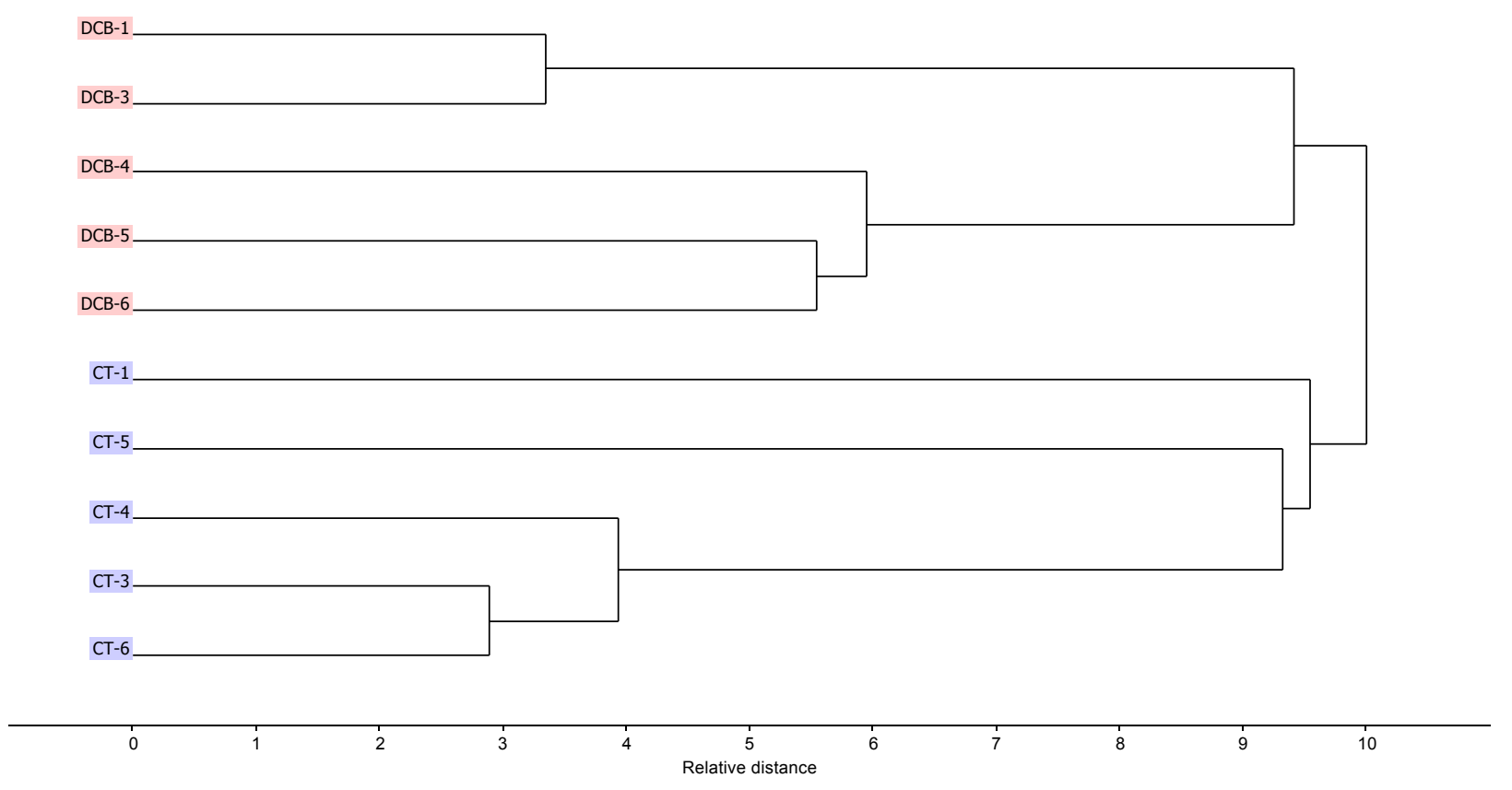

Figure S2. Dendrogram showing the hierarchical clustering of gene expression data of the 5 samples exposed to 2,5-DCB and the 5 non-exposed controls. The dendrogram was obtained by cluster analysis using the single-linkage (nearest neighbor) method and Euclidian distances (Unscrambler X version 11.0). 


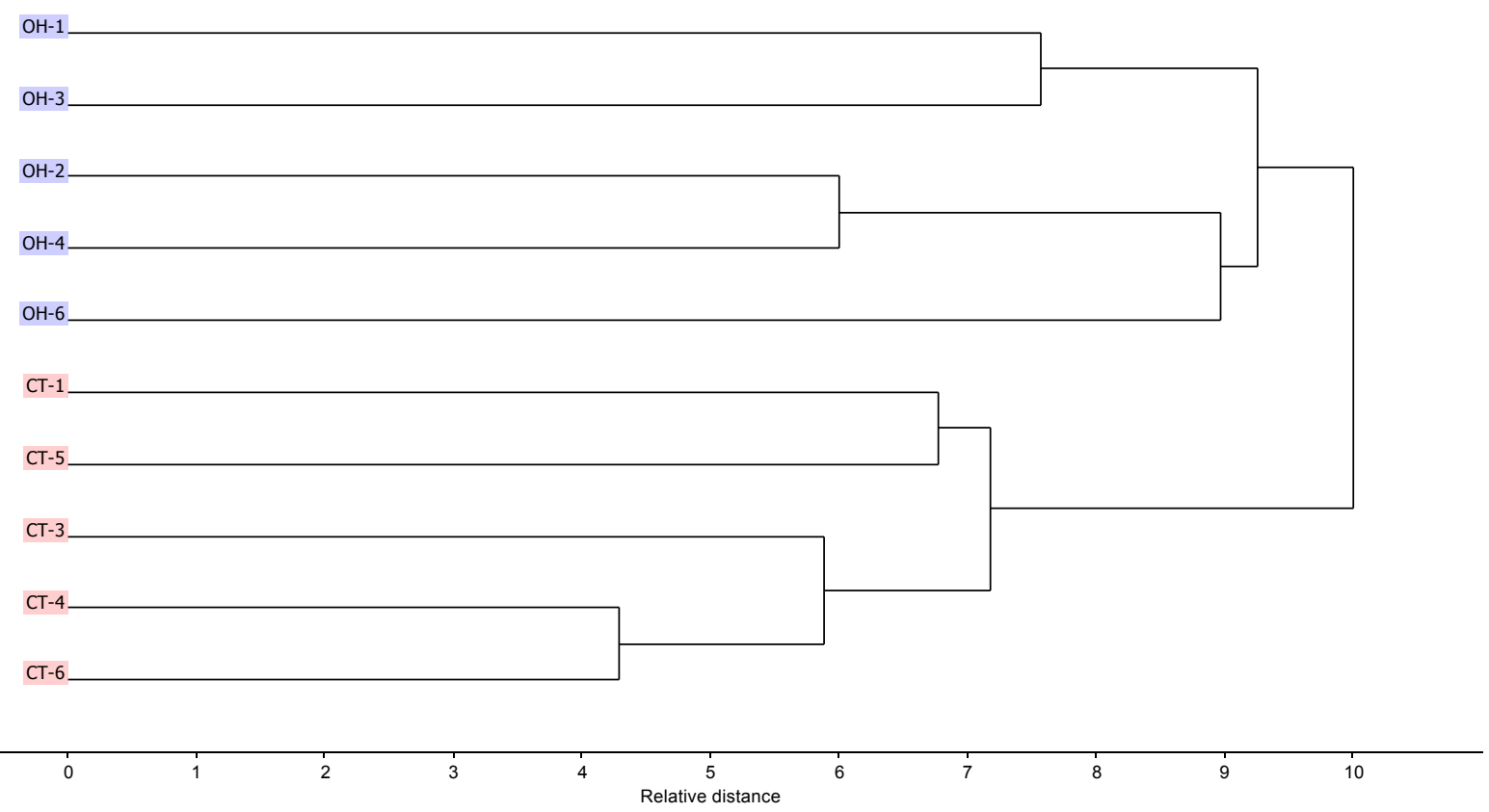

Figure S3. Dendrogram showing the hierarchical clustering of gene expression data of the 5 samples exposed to 4'-OH-2,5-DCB and the 5 non-exposed controls. The dendrogram was obtained by cluster analysis using the single-linkage (nearest neighbor) method and Euclidian distances (Unscrambler X version 11.0).
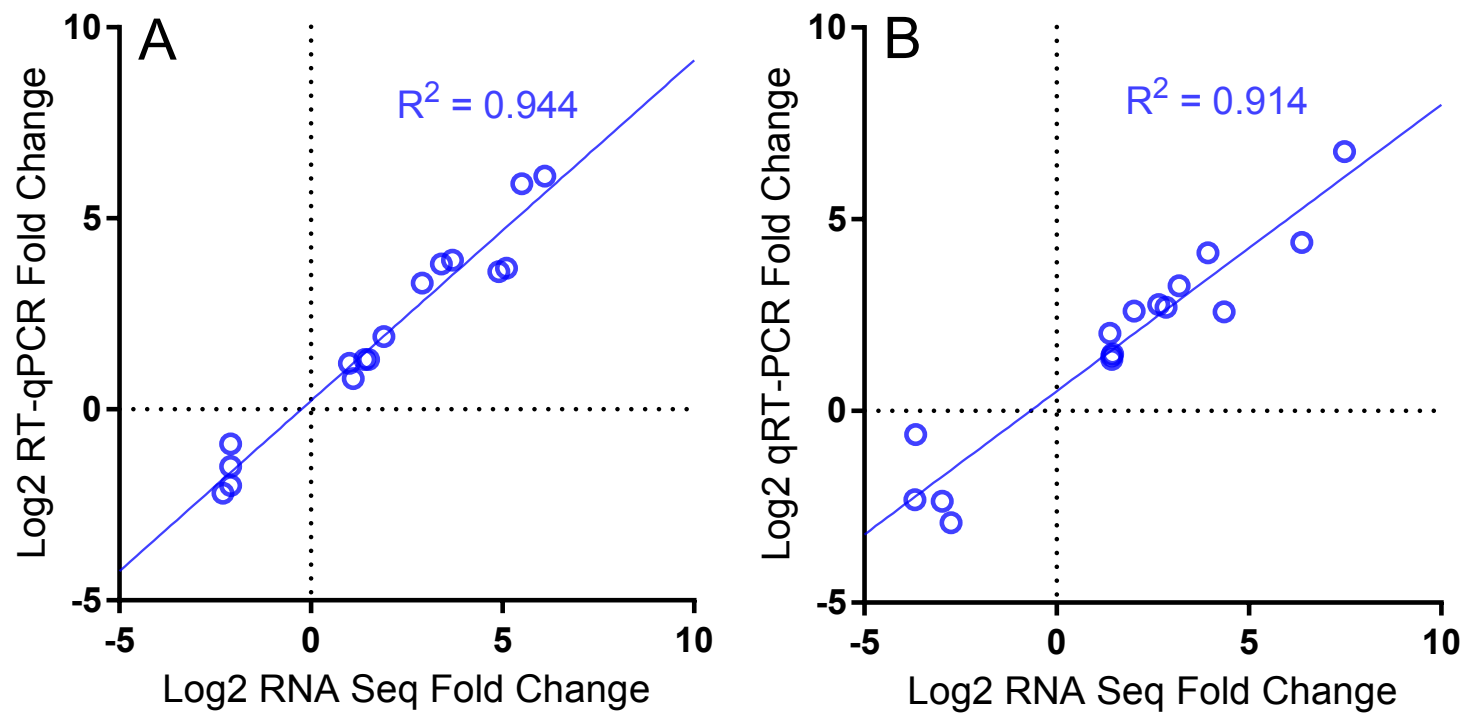

Figure S4. Scattered plots showing the fold changes of selected genes in Arabidopsis plants exposed to 2,5-DCB (Panel A) and 4'-OH-2,5-DCB (Panel B) as quantified by RNA sequencing and qRT-PCR. 


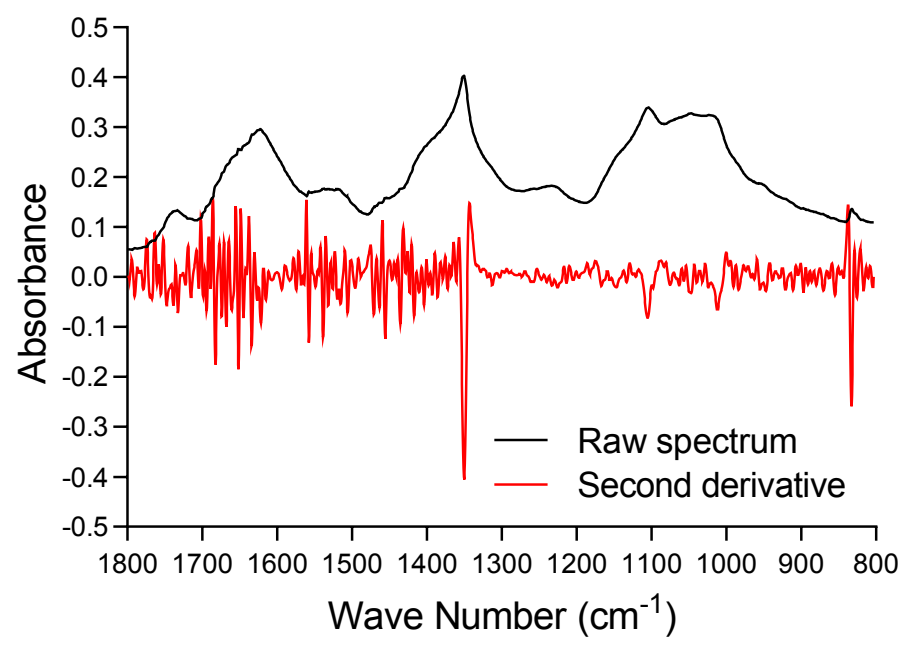

Figure S5. Example of raw and second derivative spectra of an Arabidopsis sample (nonexposed control) in the fingerprint region $\left(1800\right.$ to $\left.800 \mathrm{~cm}^{-1}\right)$. The raw spectra were processed with basic ATR correction, Savitzky-Golay second derivative filtering (15-point smooth, $2^{\text {nd }}$ polynomial order), and extended multiplicative scatter correction (EMSC) 